\title{
Novel Composite Resonance DC-DC \\ Converter with Voltage Doubler Rectifier
}

\author{
Hisatsugu KATO ${ }^{1,2}$, Hirohumi MATSUOํㅗㄹ Masaki EGUCHI ${ }^{3}$, \\ Yukitaka SAKAMOTO ${ }^{2}$, Masaki NAKAISHI ${ }^{2}$ \\ ${ }^{1}$ Nagasaki University \\ ${ }^{2}$ Tabuchi Electric Co.,LTD \\ ${ }^{3}$ Sharp Corporation \\ E-mail:h.kato@zbr.co.jp
}

\begin{abstract}
This paper deals with a novel composite resonance DC-DC converter with the voltage doubler rectifier, which is developed to be applied to the power conditioner of the photovoltaic generation system. The proposed DC-DC converter has the current and voltage resonance functions. Therefore, the output voltage regulation can be achieved for the large variations of the input voltage and load. Also, this converter has the high power efficiency. The maximum power efficiency $96.1 \%$ can be realized.
\end{abstract}

\section{I .INTRODUCTION}

Recently, there is an increasing spread in the photovoltaic generation system [1,2] all over the world because many persons are interested in the clean energy system from the viewpoint of the ecological problem. In this paper, a novel composite resonance DC-DC converter is proposed and developed, in which the current and voltage resonances [3-5] and the voltage doubler rectifier are employed as the power conditioner of the photovoltaic generation system. The output voltage can be regulated for the large variations of the input voltage and load because of the current and voltage resonance circuits. Also, the high power efficiency can be achieved by using not only the composite resonance but also the voltage doubler rectifier. Furthermore, the burst oscillation control is used to improve the power efficiency under the condition that the input voltage is high and the load is light.

\section{II .CIRCUIT CONFIGURATION}

Fig.2.1 shows the proposed composite resonance DC-DC converter with the voltage doubler rectifier, in which the current and voltage resonance circuits are employed. In this figure, Q1 and Q2 are main switches of IGBTs. $\mathrm{Cv}$ and $\mathrm{Ci}$ are the voltage and current resonance capacitors. L1 and L2 are inductances of the primary and secondary windings of the transformer $\mathrm{T}$. The leakage inductance $\mathrm{Li}$ is used, which exists between the primary and secondary windings of $\mathrm{T}$. The voltage doubler rectifier is composed of the diodes D1 and
D2, and capacitances $\mathrm{Cd}$ and Co. The IGBT switches Q1 and Q2 are turned-on and turned-off alternatively. There exists the short dead time between the on-times of Q1 and Q2.

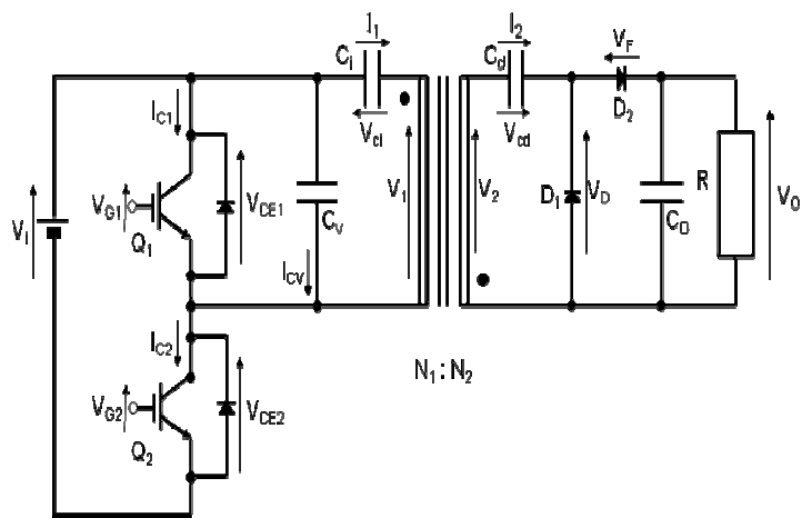

Fig.2.1 Proposed voltage and current resonance DC- DC converter with the voltage doubler rectifier.

\section{III.STATE OF OPERATION AND OPERATIONAL MODE}

(A) Operational Mode 1

STATE- 1

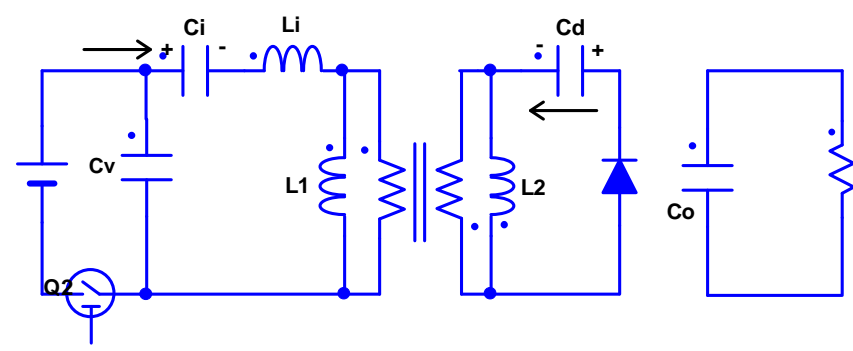

(a) state-1 (D1 and Q2 only are on)

Fig.3.1

The current Ic2 flowing in the IGBT switch Q2 is in the state of the current resonance by capacitance $\mathrm{Ci}$ and inductance L1. at this time, on the secondary side, diode D1 is on and the charge is charged to capacitance $\mathrm{Cd}$ for the voltage doubler. From state-1,the input voltage and primary winding current become the next expressions. 
$V_{i}=\left(L_{i}+L_{1}\right) \frac{d I_{1}}{d t}+V_{C i}$

$I_{1}=C_{i} \frac{d V_{C i}}{d t}$

From these expressions, primary windings current and the voltage across current resonance capacitance $\mathrm{Ci}$ become the next expressions.

$I_{1}=\frac{V_{i}}{Z_{1}} \sin \omega_{i} t$

$V_{C i}=V_{i}\left(1-\cos \omega_{i} t\right)$

Moreover the secondary windings current and the voltage across capacitance $\mathrm{Cd}$ for the voltage doubler become the next expressions.

$I_{2}=C_{d} \frac{d V_{C d}}{d t}$

$V_{C d}=-L_{2} \frac{d I_{2}}{d t}$

$\omega i$ and $\mathrm{Zi}$ are as follows.

$$
\begin{aligned}
& \omega i=\frac{1}{\sqrt{\left(L_{i}+L_{1}\right) C_{i}}} \\
& Z_{i}=\sqrt{\frac{\left(L_{i}+L_{1}\right.}{C_{i}}}
\end{aligned}
$$

\section{STATE-2}

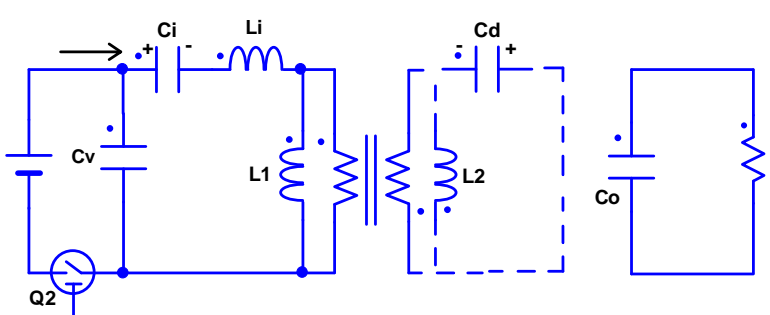

(b) state-2 (Only Q2 is on)

Fig.3.1

As well as state- 1 , it is in the state of the current resonance by capacitance $\mathrm{Ci}$ and inductance L1. However, diode D1 is off by charge charged capacitance $\mathrm{Cd}$, and the current doesn't flow to the secondary side. As a result, the change disappears almost as for the voltage and the current on the primary side.

\section{STATE-3}

The IGBT switch Q2 is off, and the voltage $\mathrm{V}_{\mathrm{CE} 1}$ between the drain and the source is in the state of the voltage resonance by the capacitance $\mathrm{Cv}$ and the self-inductance of transformer connected with the IGBT switch Q2 in parallel. The voltage across voltage resonance capacitor $\mathrm{Cv}$ and the primary winding current become the next expressions.

$$
\begin{aligned}
& V_{C v}=\left(L_{i}+L_{1}\right) \frac{d I_{1}}{d t}+V_{C i} \\
& I_{1}=-C_{V} \frac{d V_{C i}}{d t}
\end{aligned}
$$

From these expressions, the voltage across capacitance $\mathrm{Cv}$ becomes the next expression..

$$
V_{C v}=V_{C i} \omega_{v} \sin \omega_{v} t
$$

It is understood that it is in the state of the voltage resonance from this expression.

$\omega \mathrm{i}$ is as follow.

$$
\omega_{v}=\frac{1}{\sqrt{\left(L_{i}+L_{1}\right) C_{V}}}
$$

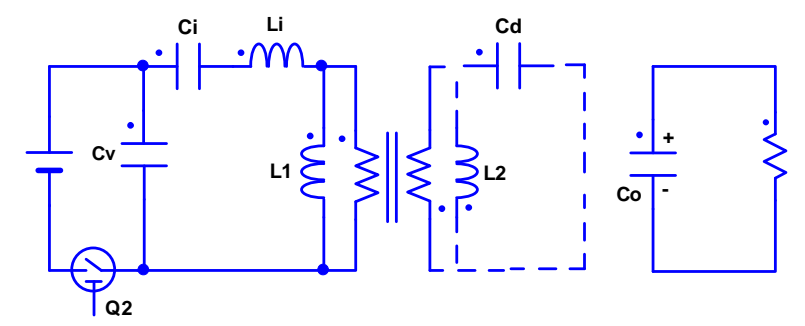

(c) state-3 (All of IGBTs and diodes are off) Fig.3.1

\section{STATE-4}

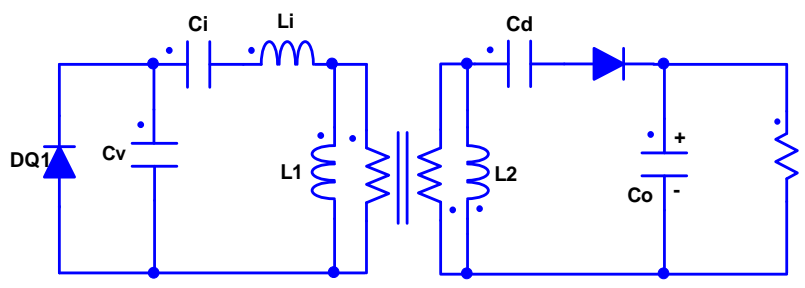

(d) state-4 (Only DQ1 and D2 are on)

Fig.3.1

The state of the voltage resonance works end, and the diode D1 and D2 are on. The period of these the state -3 and the state -4 are the dead time. And the voltage of VCE1 turns and after it becomes zero volt, the IGBT switch Q2 is on and it is in the state of zero voltage switching.

\section{STATE-5}

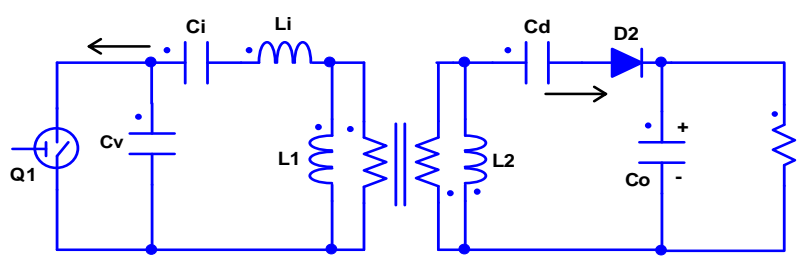

(e)state-5 (Only Q1 and D2 are on) Fig.3.1 
The IGBT switches Q2 and diode D2 are on and on the primary side, the charge charged capacitance $\mathrm{Ci}$ is discharged as a result, it is in the state of the current resonance by the leakage inductance $\mathrm{Li}$. And on the secondary side, the charge charged capacitance $\mathrm{Cd}$ for the voltage doubler flows into the output. At this time, the secondary output voltage and the secondary winding current become the next expressions.

$V_{O}=L_{2} \frac{d I_{2}}{d t}+V_{C d}$

$I_{2}=C_{d} \frac{d V_{C d}}{d t}$

From these expressions, the secondary winding current becomes the next expression.

$I_{2}=\frac{V_{O}}{Z_{2}} \sin \omega_{2} t$

On the secondary side, it is understood that it is in the state of the current resonance from this expression.

$\mathrm{Z} 2$ and $\omega 2$ are as follows.

$Z_{2}=\sqrt{\frac{L_{2}}{C_{d}}}$

$\omega_{2}=\frac{1}{\sqrt{L_{2} C_{d}}}$

\section{STATE-6}
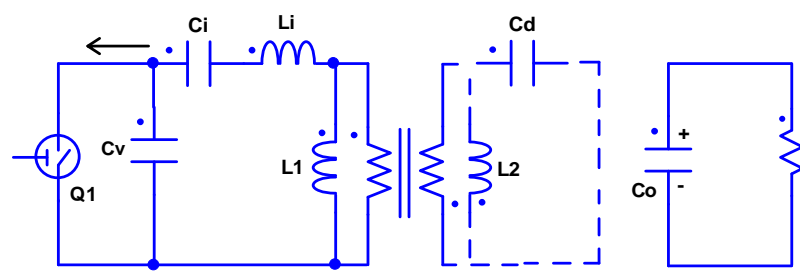

(f) state-6 (Only Q1 is on)

Fig. 3.1

The diode D2 is off by the charge charged capacitance $\mathrm{Co}$, and the secondary winding current I2 doesn't flow.

\section{STATE-7}

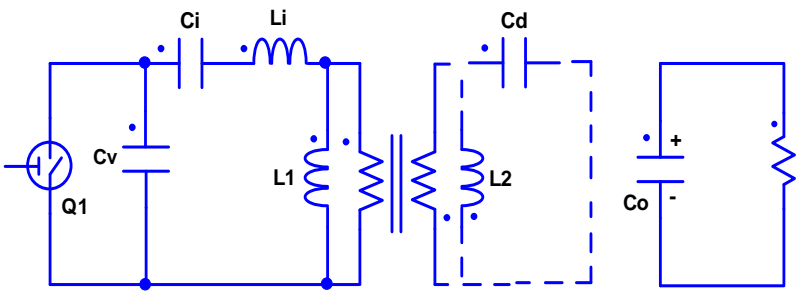

(g) state-7 (All of IGBTs and diodes are off)

Fig.3.1
All of IGBTS and diodes are off, and it is in the state of the voltage resonance by capacitance $\mathrm{Cv}$.

\section{STATE-8}

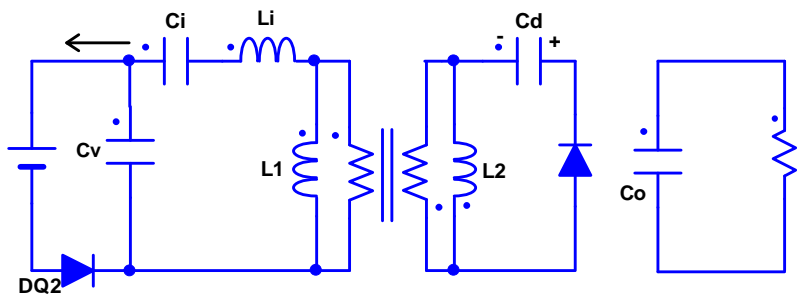

(h) state-8 (Only DQ2 and D1 are on) Fig.3.1

Only DQ2 and D1 are on and it is in the state of zero voltage switching.

\section{(B) Operational Mode 2}

In the state- 1 and the state- 5 of Fig.3.2, the same circuit as the state- 1 and the state- 5 of operational mode 1 operate.

STATE-9

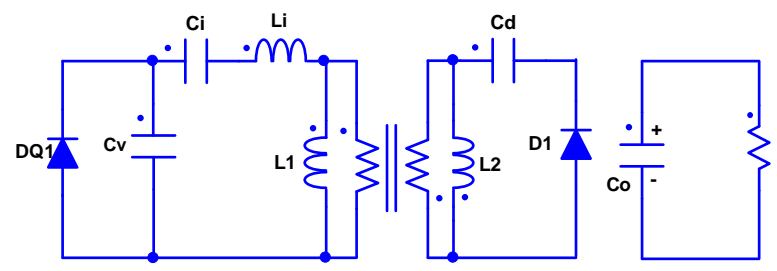

(i)state9 (Only DQ1 and D1 are on) Fig.3.1

Only DQ1 and D1 are turned-on, it is in the voltage resonance by the capacitance $\mathrm{Cv}$.

STATE-10

Only DQ1 and D2 are on, and it is in the voltage resonance.

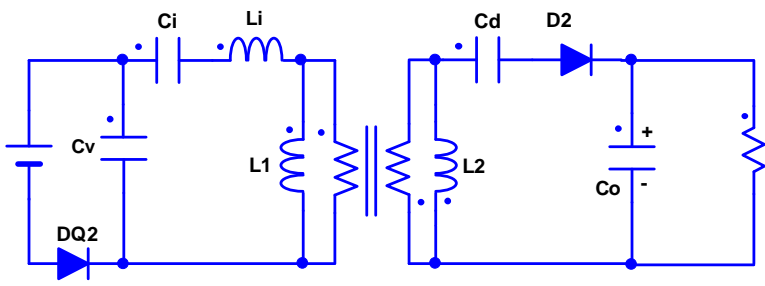

(j)state-10 (Only DQ2 and D2 are on) Fig.3.1 Equivalent circuit of Fig.2.1 


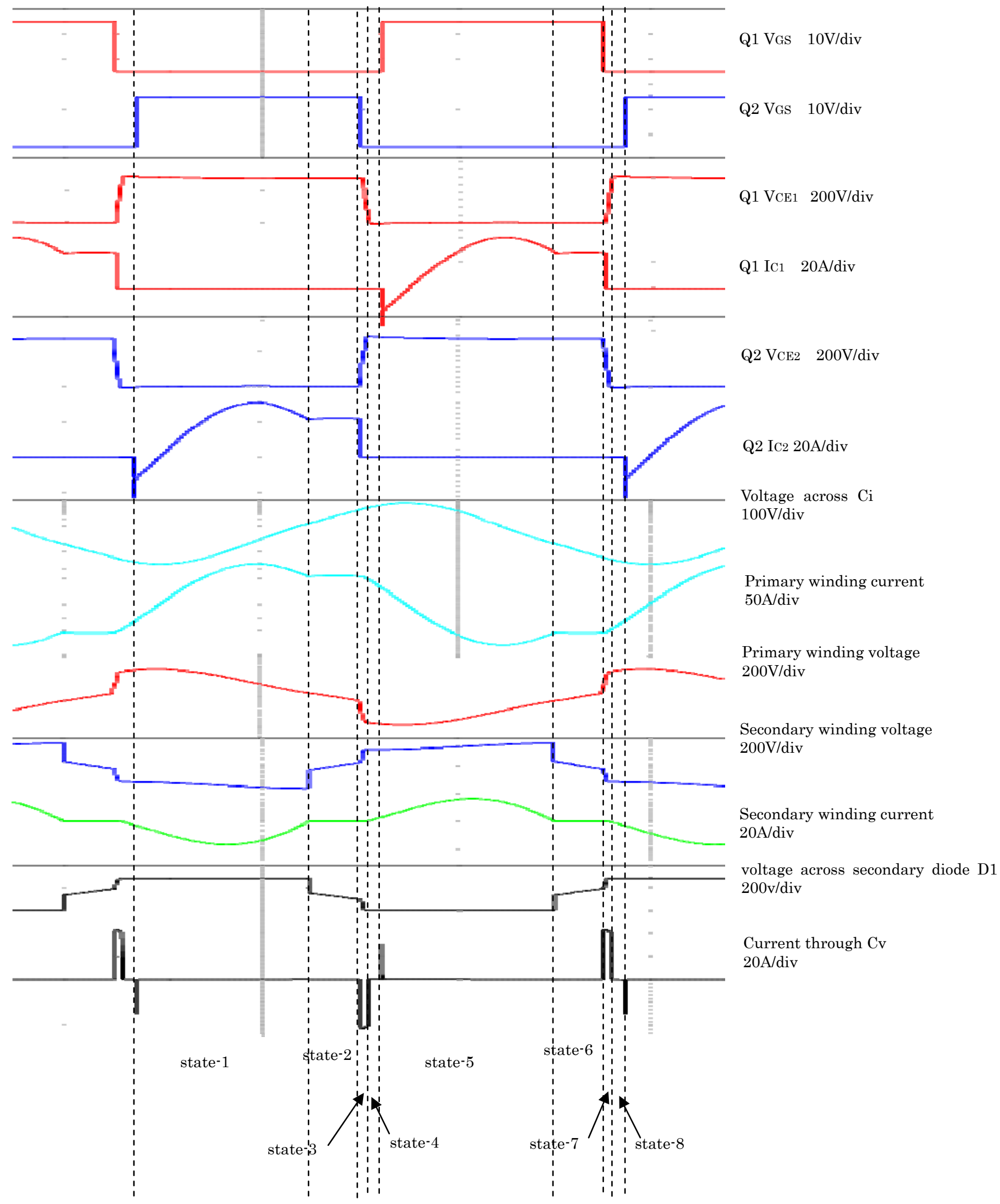

Fig.3.2 Simulation waveforms of operational mode 1 


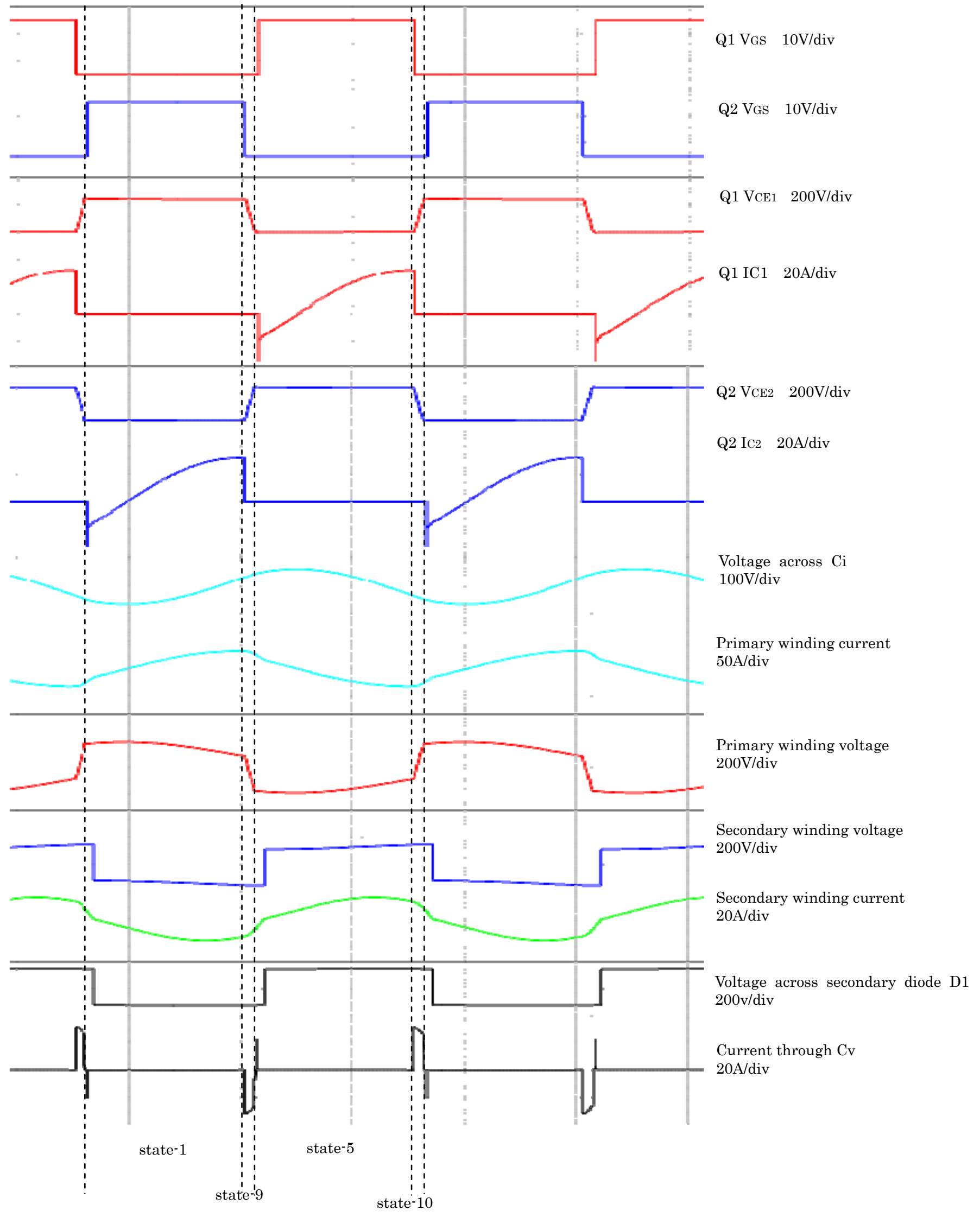

Fig.3.3 Simulation waveforms of operational mode 2 
IV.COMPARISON BETWEEN MEASURING

WAVEFORM AND SIMULATION RESULT

Fig.4.1 shows the simulation and observed waveforms. It is seen Fig.4.1 that the simulation result is agreed well with the observed one.
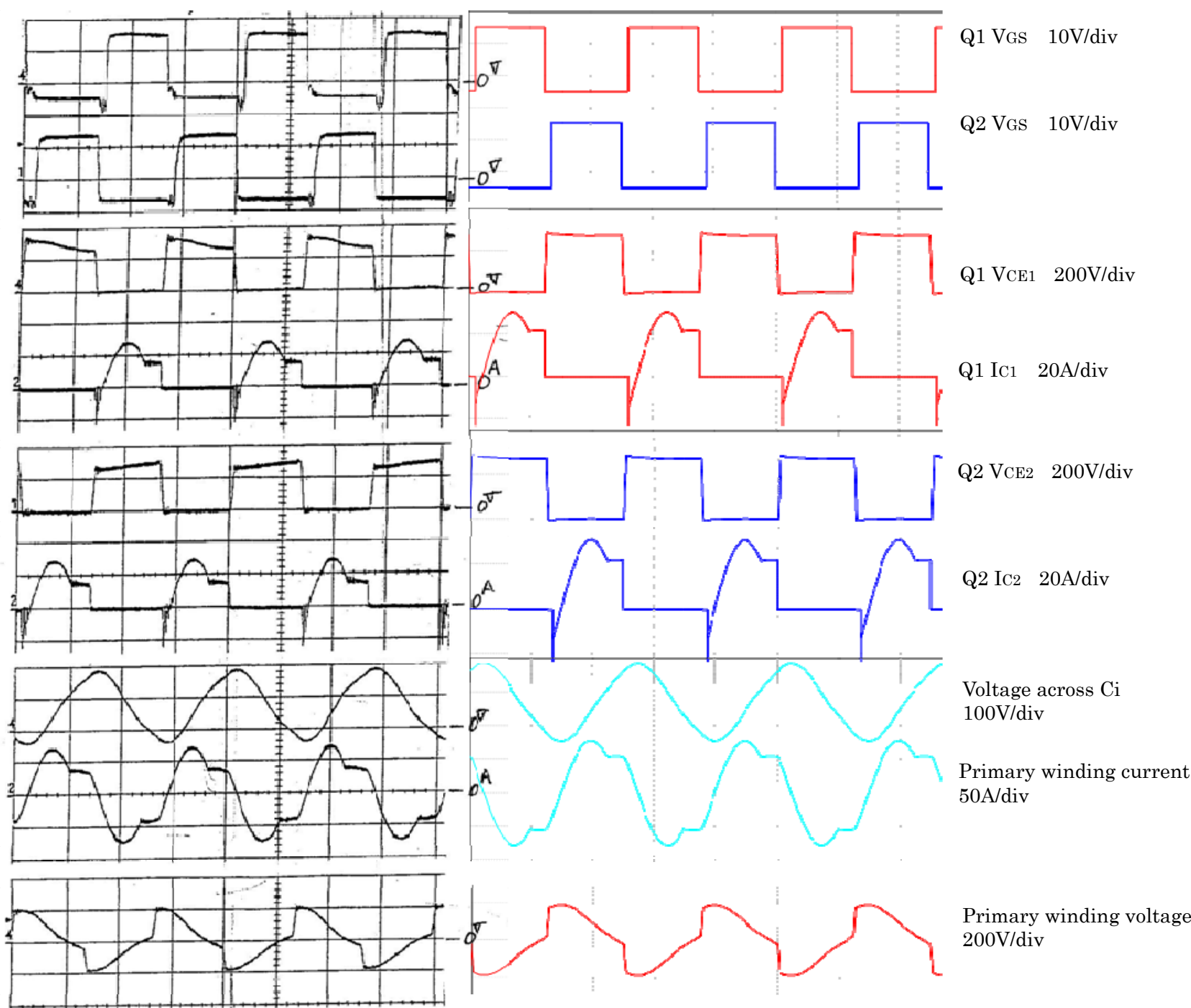

Primary winding voltage 200V/div

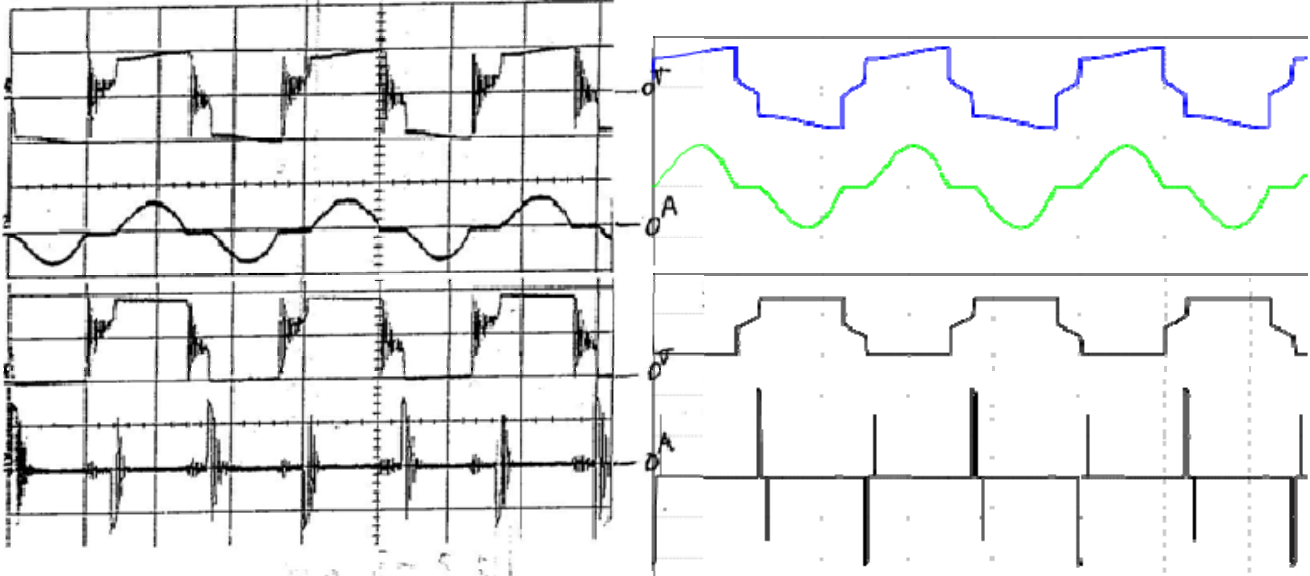

Secondary winding voltage 200V/div

Secondary winding current 20A/div

Voltage across secondary diode D1 200v/div

Current through $\mathrm{Cr}$ $20 \mathrm{~A} / \mathrm{div}$

Fig.4.1 Simulation and observed waveforms 


\section{V.POWER EFFICIENCY}

\section{(A) Under Heavy-Load Condition}

Fig.5.1 shows the power efficiency characteristics under the heavy-load of the proposed DC-DC converter. The maximum power efficiency is $95.7 \%$ at $230 \mathrm{~V}$ DC of the input voltage and $900 \mathrm{~W}$ of the output power.

\section{(B) Under Light-Load Condition}

Under the condition that the input voltage is high and the load is light, the burst oscillation control is used to improve the power efficiency and to expand the sphere of control.Fig.5.2 shows the power efficiency characteristics under the light-load of the proposed DC-DC converter. The maximum power efficiency is $95.2 \%$ at $240 \mathrm{~V}$ DC of the input voltage and $400 \mathrm{~W}$ of the output power and is $93.2 \%$ at $300 \mathrm{~V}$ DC of the input voltage and $200 \mathrm{~W}$ of the output power. The drop of the efficiency at $200 \mathrm{~W}$ of the output can be improved by adjusting the burst -oscillation condition.

\section{VI.CONCLUSION}

It proposed a novel composite resonance DC-DC converter with the voltage rectifier for the power conditioner of the photovoltaic generation system. The maximum power efficiency $96.1 \%$ can be realized at $290 \mathrm{~V}$ DC of the output voltage and $600 \mathrm{~W}$ of the output power.

\section{VII.REFERENCES}

[1]Yosimi Horiuchi,Hironori Nisihara,Takashi Ujiie," New Energy Power Generating System at Fuji Electric Co., Ltd. Ability Development Center", Fuji Electric Co., Ltd. Technical Report, Vol.75 No.5,pp.281-284, 2002

[2]Hiroaki Endo, Shinya Yokoyama, Takafumi Takuma,Masahide Yamaguchi , Haruhiko Mizuta,Yasuhito Sugimura,"Application of Battery Combined Photovoltaic Generation System for DisasterProof House, ” Journal of Japan Institute of Power Electronics, Vol.31,pp.109-114,March2006

[3]C.F.Jin,T.Ninomiya,S.Tomioka,"Dynamic Characteristics of LLC Current-Resonant DC-DC Converter", IEICE Technical Report, EE2008-35,pp.1-6,October 2008

[4]Koichi Morita," Ultra Low-noise switch-mode Power Supply", Journal of Japan Institute of Power Electronics Electronics,Vol.30, pp.4-11,March 2004

[5]Masakazu Gekinozu, yukihiro Nishikawa, Takeshi Nozawa, "DC-DC Transformational Technology for Switching Power Supply” ,Fuji Electric Co., Ltd. Technical Report, Vol.75 No.8, pp.456-459 2002

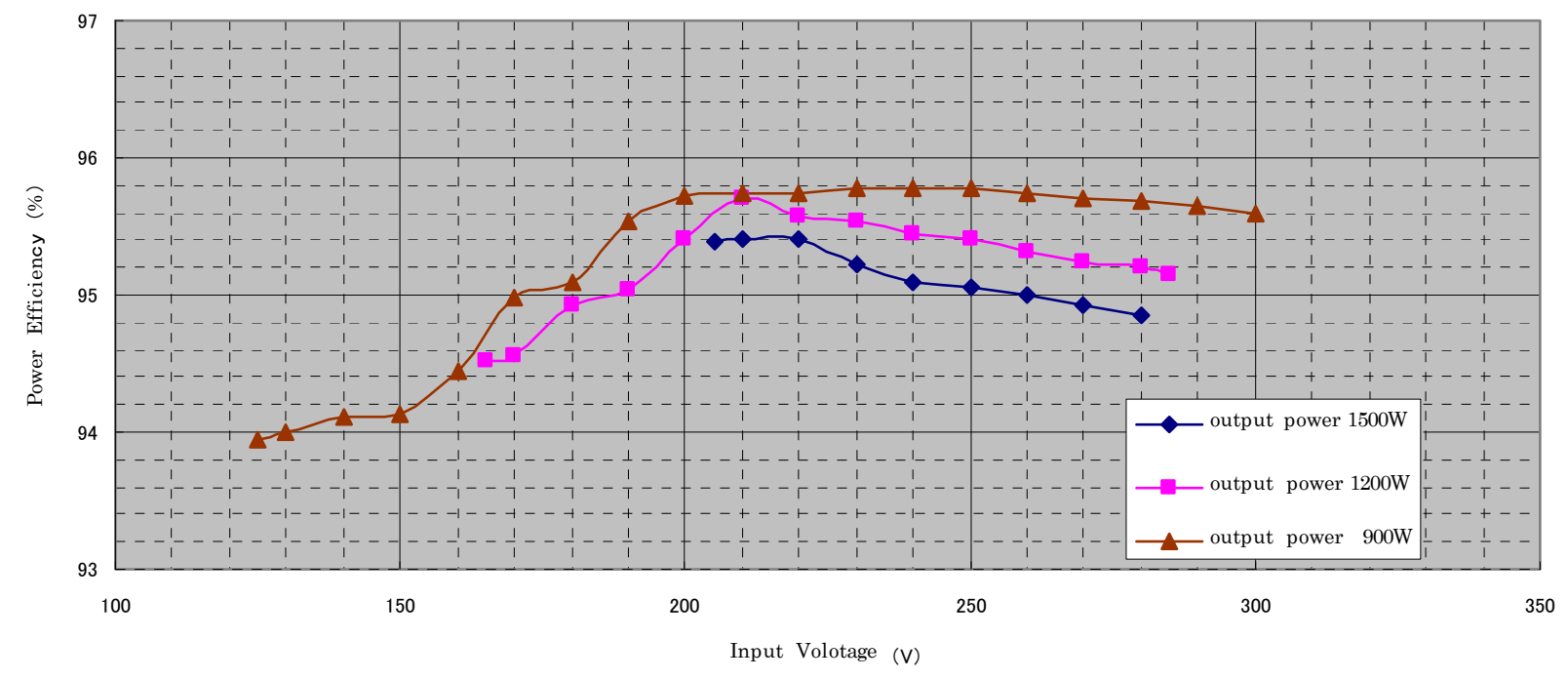

Fig.5.1 Power Efficiency Characteristics (heavy-load) 


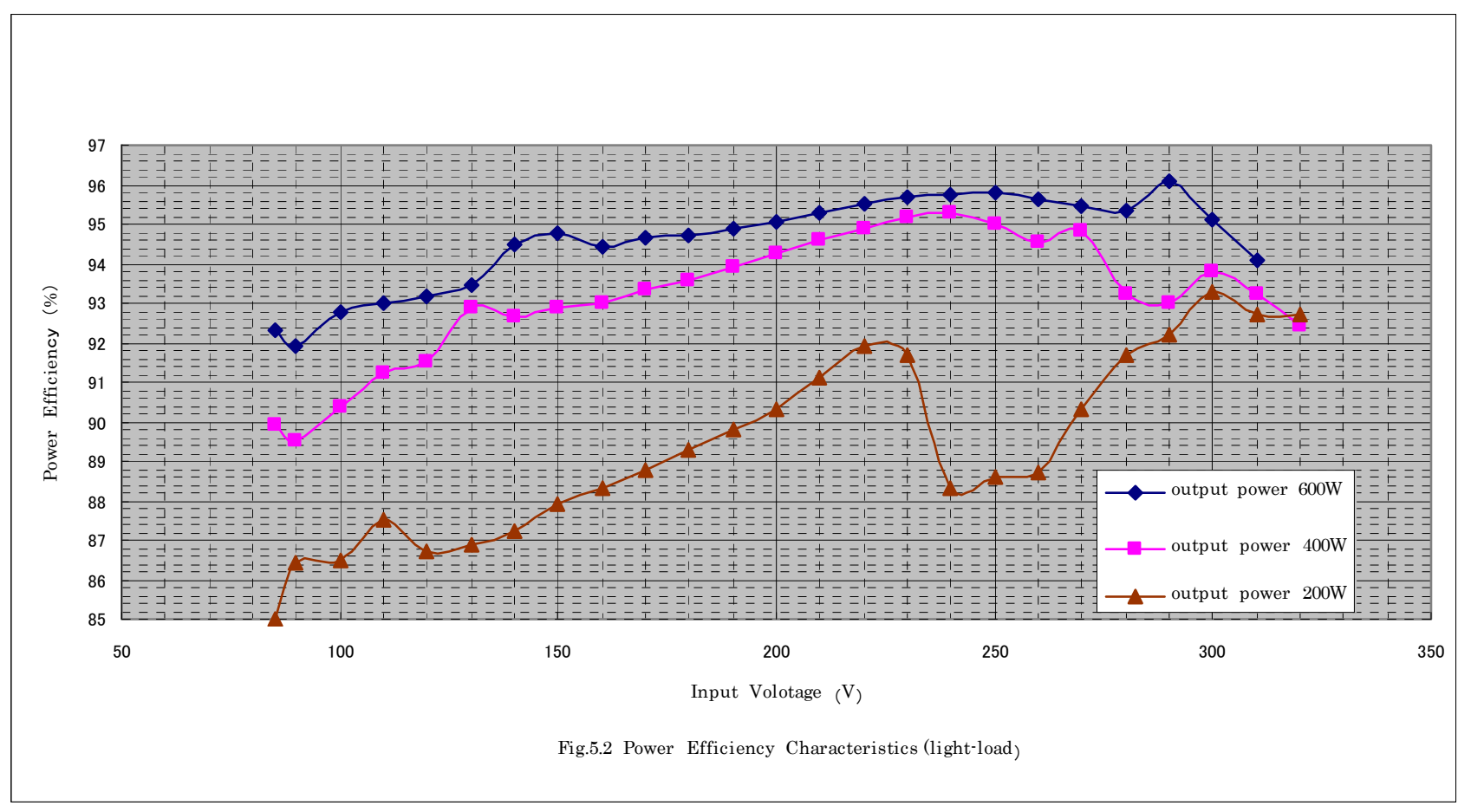

